\title{
EXTRACURRICULAR SPORTS IMPROVE BALANCE SKILLS IN CHILDREN WITH VISUAL DISABILITY
}

\author{
Irena Lyudmilova, Diana Dimitrova \\ National Sports Academy "Vassil Levski", Sofia, Bulgaria
}

\begin{abstract}
The importance of the visual abilities for the normal balance skills is well studied. However, it is not fully clarified how the severity of visual impairment of children and adolescents disturbs the balance and the impact of physical activity on this component of fitness. This study is aiming at establishing the importance of extracurricular physical activity on the balance abilities of school-aged children with visual disabilities considering their sex, age, and degree of impairment. Two hundred and nineteen children and adolescents with visual impairment, aged between 12 and 19 years, participated in this study. The participants were divided into groups according to the age (12-14 y., 15-17 y., and 18-19 y.), sex, visual impairment (with low vision and blind), and level of physical activity (with and without extracurricular sport participation). The balance skills were measured by the time in seconds for single-leg balancing. Ordinary statistic for describing variations was employed. The balance skills of visually impaired children increased with age. There were no significant differences $(p<0.05)$ in the balance between the sexes in all age groups. Balance skills comparison of the children, having different degrees of visual impairment also registered similar results in both groups. The female and male children and adolescents from all age groups who participated in extracurricular sports scored better in the balance test $(p<0.05)$.

This study characterized the balance skills of children with different levels of visual disability across age in both sexes, and confirmed the positive effect of physical activity on this fitness component.
\end{abstract}

Key words: visual impairments, balance skills, sports activities

\section{INTRODUCTION}

Vision is essential for most everyday activities and independent lifestyle of healthy individuals. Visual impairment has an impact on accessing visual information. According to Barati et al. (2013) humans obtained almost $80-90 \%$ of information through visual perception. The authors also emphasize the role of eye-sighting significance for social relationships.

Due to physical and psychosocial constraints, disable children are more physically unfit than their counterparts with normal vision (Longrnuir \& Bar-Or, 2000). Numerous authors confirmed the impaired vision negative effects on physical work capacity, posture, balance, and orientation (Abolfotouh \& Telmesani, 1993, Çolak et al., 2004, Juodžbalienė \&, Muskus, 2006, Portfors-Yeomans \& Riach, 1995, Sundberg, 1982).

Maintaining body balance plays a key role in the development of motor abilities, physical fitness and spatial orientation of blind and visually impaired children (Rutkowska \& Skowronski, 2007). Balance can be classified either as static or as dynamic. Static balance is the ability to maintain postural stability and orientation with a centre of mass over the base of support and body at rest (O'sullivan \& Portnry, 2014). To be able to balance statically the body's center of gravity must be lined up above your center of support. While standing on two legs, the center of support is between the two feet. While standing on one leg, it is fixed upon the center of the standing foot. Dynamic balance is the ability to maintain postural stability and orientation with a centre of mass over the base of support while the body parts are in motion (O’sullivan \& Portnry, 2014).

It is well recognized that physical activity affects positively many aspects of a child's health and motor abilities (King et al., 2013). This research suggests that practicing sports is beneficial for visually impaired and blind athletes (Çolak, 2014). Researchers have emphasized also the importance of the physical exercises for the balance function development in people with visual impairment (Bilge, 2019, Çalık, 2019).

However, it is not fully clarified to what extent the visual impairment severity disturbs balance skills 
in children and adolescents, as well as the sports activities influence on balance skills in visually impaired students. Therefore, this study is aiming at establishing the importance of extracurricular physical activity on the balance abilities of schoolaged children with visual disabilities considering their sex, age, and degree of impairment.

\section{MATERIALS AND METHODS}

The study was approved ethically by the Ethical board of National Sports Academy and was performed by following the Helsinki Declaration, revised 2013.

A total sample of 219 children and adolescents (124 boys and 95 girls), aged between 12 and 19 years, students at both special schools for visually impaired children in Bulgaria, participated in the study. The children from both sexes were divided into three age groups (12-14, 15-17, and 1-19 years old), and into two groups according to their visual impairment (blind students and students with low vision (Table 1). Their visual impairment information was obtained from the school ophthalmologists of both special schools. Students classification into groups was based on the WHO (WHO. ICD-10 Version:2010) definitions according to which "low vision" is visual acuity less than $6 / 18$ but equal to or better than $3 / 60$, or a corresponding visual field loss to less than 20 degrees in the better eye with the best possible correction (ICD - 10 visual impairments categories 1 and 2), and "blindness" is visual acuity of less than $3 / 60$, or a corresponding visual field loss to less than 10 degrees in the better eye with the best possible correction (ICD - 10 visual impairments categories 3,4 and 5).

Table 1. Distribution of the students in groups according to age, sex, degree of visual impairment and level of physical activity

\begin{tabular}{|l|c|c|c|c|c|c|}
\hline \multirow{2}{*}{\multicolumn{1}{c|}{$\begin{array}{c}\text { Variable / } \\
\text { Sex and age group }\end{array}$}} & \multicolumn{3}{c|}{ Girls } & \multicolumn{3}{c|}{ Boys } \\
\cline { 2 - 8 } & $\begin{array}{c}\mathbf{1 2 - 1 4} \\
\text { years }\end{array}$ & $\begin{array}{c}\mathbf{1 5 - 1 7} \\
\text { years }\end{array}$ & $\begin{array}{c}\mathbf{1 8}-19 \\
\text { years }\end{array}$ & $\begin{array}{c}\mathbf{1 2 - 1 4} \\
\text { years }\end{array}$ & $\begin{array}{c}\mathbf{1 5 - 1 7} \\
\text { years }\end{array}$ & $\begin{array}{c}\mathbf{1 8 - 1 9} \\
\text { years }\end{array}$ \\
\hline Blind students & 19 & 16 & 13 & 18 & 16 & 12 \\
\hline Students with low vision & 15 & 18 & 14 & 28 & 25 & 25 \\
\hline $\begin{array}{l}\text { No additional sports } \\
\text { participation }\end{array}$ & 22 & 23 & 18 & 26 & 22 & 20 \\
\hline $\begin{array}{l}\text { Extracurricular sports } \\
\text { participation }\end{array}$ & 12 & 11 & 9 & 20 & 19 & 17 \\
\hline
\end{tabular}

The students were also divided into two groups according to their level of physical activity: a) students practicing extracurricular sports, and b) students not practicing sports. All students used to follow regular adapted physical education classes 3 times per week, 45 minutes each. The group of the students with extracurricular sports program practices additional 90 minutes sports (goalball, track and fields, judo or martial arts) twice per week.

The static balance skills of the subjects were measured by the time in seconds for single-leg balancing on the dominant leg. For $76,7 \%(n=168)$ of assessed children dominant was the right leg, and for $23,3 \%(n=51)$ of them the left. Descriptive statistics (mean \pm standard deviation) were computed for all variables. Statistical significance between means was tested by independent samples t-test. An alpha level of $p<0.05$ was used to establish significance for all procedures.

\section{RESULTS}

Figure 1 presents the results of the comparison between age- and sex groups in students with impaired vision. As shown in Figure 1 the balance skills of visually impaired children and adolescents increased with age. The mean time in sec. for balancing on one leg was $22.6 \mathrm{sec}$ for the 12 years old boys and $19.1 \mathrm{sec}$ for girls, 12 years of age. For the 19 old, these values were respectively boys - 36.8 sec and girls - $38.1 \mathrm{sec}$. There were no significant differences in balance maintaining between the sexes in all age groups. 


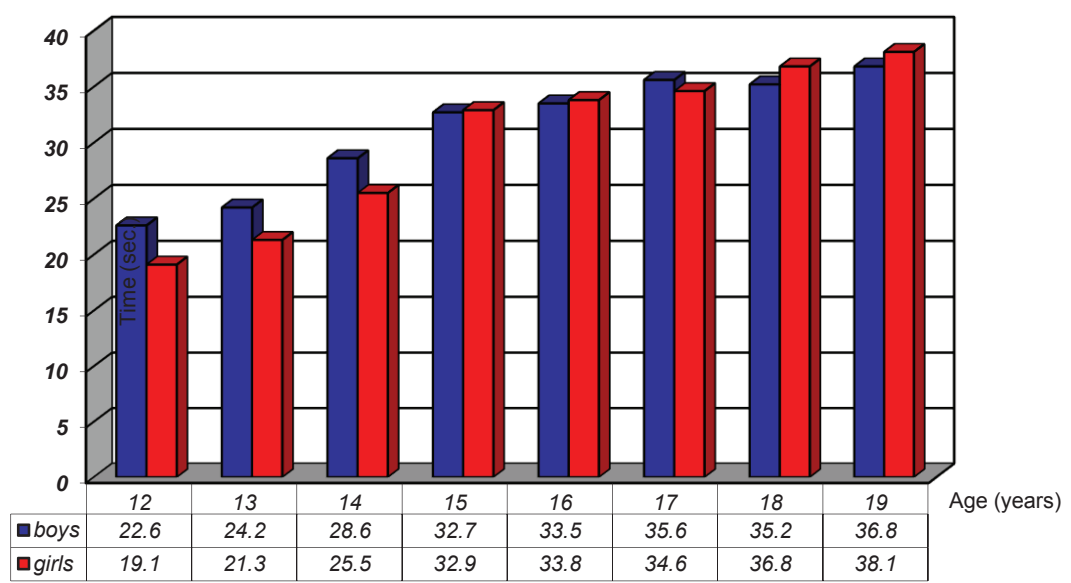

Note: Statistical significance between means $(p \leq 0.05)$ for the respective groups in boys ${ }^{*}$ and in girls ${ }^{*}$

Figure 1. Balance skills in impaired vision students in relation to age and sex The balance skills comparisons of the students with ance skills as the group of blind children (Figure 2). different degrees of visual impairment showed that The differences between both sexes in the three age the group with low or partial vision had similar bal- groups were insignificant.

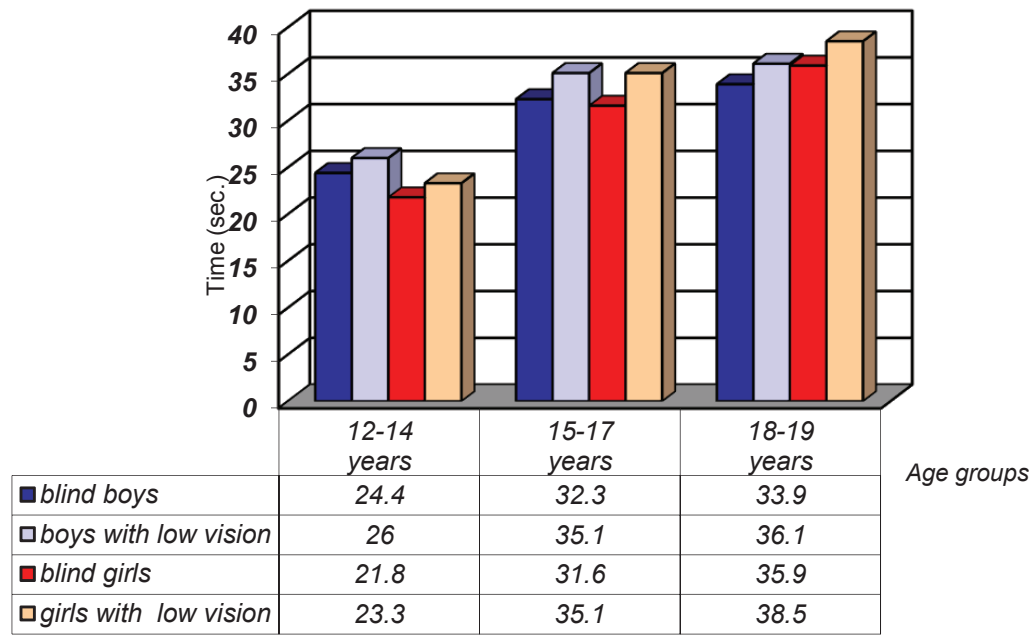

Note: Statistical significance between means $(p \leq 0.05)$ for the respective groups in boys ${ }^{*}$ and in girls ${ }^{*}$

Figure 2. Balance skills of children and adolescents with total and partial visual loss

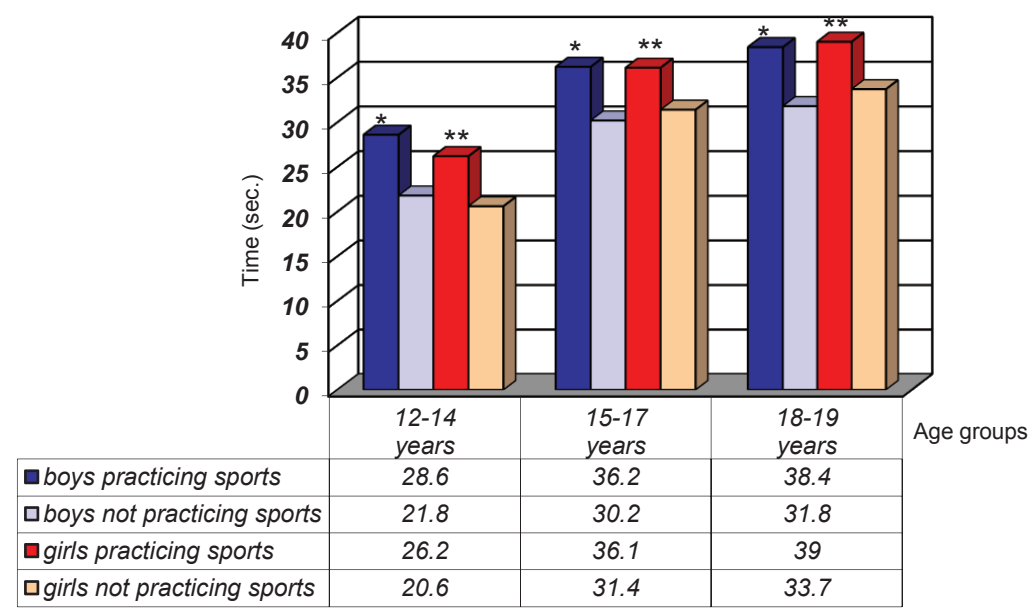

Note: Statistical significance between means $(p \leq 0.05)$ for the respective groups in boys ${ }^{*}$ and in girls ${ }^{*}$ 
Figure 3. Balance skills in visually impaired children and adolescents with different levels of sports activity

The participation in additional sports activities (athletics, goalball, judo, martial arts) resulted in an improvement in balance abilities of visually impaired children and adolescents. The students from both sexes who participated in extracurricular sports activities performed better than those who participate only in physical education classes. The differences were significant for the three age groups in both sexes (Figure 3).

\section{DISCUSSION}

Balance skills of the tested children and adolescents, both sexes, manifested improvement with the age. These results are in agreement with the data of the other authors (Rutkowska et al., 2015). Similar trend was observed for the eye-sighted general population (Slanchev P. et al. 1992). Nevertheless, significant differences between children with and without visual impairment on single-leg balance performance were registered (Uzunović, 2015). Researchers found evidence to support delays in motor acquisition of school-aged individuals with visual impairments compared to age-matched eye-sighted counterparts without such disabilities (Haegele ET AL., 2015). In general, the studies confirmed that visually impaired children have a lower level of health-related physical fitness than their eye-sighted peers (Kozub \& Oh, 2004, Lieberman et al., 2002). However, it is not fully clear to what extent the degree of visual impairment limitation affects the balance skills of children and adolescents. Some authors did not observe any statistical difference between the fitness score of children with low vision and those who are blind (Kozub \& Oh, 2004, Lieberman et al., 2002). Recent results of Rutkowska et al. (2015) indicated that the ability to maintain balance is associated with the degree of visual impairment and partially eye-sighted people demonstrate better results than the blind (Rutkowska et al., 2015). However, there are even research studies showing that totally blind pupils may maintain equilibrium better than legally blind subjects (Juodžbalienè \& Muskus, 2006). Our study failed to detect any difference between students from both groups according to the degree of visual impairment in both sexes. Some authors explained this lack of difference by the development of compensatory vestibular and proprioceptive mechanisms in children with different severity of visual impairments (Rutkowska \& Skowronski, 2007).
The main finding of our study was that the visually impaired students who practice extracurricular sport perform better on the balance test than those who participate only in physical education classes. This means sports activities in childhood and adolescence may improve the balance skills of visually impaired children and, to some extent, compensate for this motor skill deficit. Although many authors recommend exercise and sports for this population, there are only a few studies addressing intervention programs for improving the visually impaired children's balance (Aki et al., 2007). Bilge at al. (2019) studied the positive effects of 8 weeks specialized exercise program on balance abilities of congenitally blind children. The same author emphasizes that it can be assumed that rehabilitation programs for blind children are currently lacking, and that they should be widely implemented to improve the balance. Perrin et al. (2002) reported that long-term sporting activity could improve dynamic and static postural control in daily life activities.

\section{CONCLUSION}

The results of this research study demonstrated that children and adolescents with visual impairments across all age groups who participate in additional sport activities show higher balance test scores than those who follow only regular physical education lessons. It can be assumed that adapted and specialized sports for the blind occur to be strong tools for achievement of a better balance skills, and this maybe is a prerequisite tor develop a higher level of basic motor skills related to physical fitness and quality of life.

\section{REFERENCES}

Aki, E., Atasavun, S., Turan, A., Kayihan, H. (2007). Training motor skills of children with low vision. Perceptual and Motor Skills, Vol. 104, No. 3(pt. 2), pp. 1328-1336.

Abolfotouh, M., Telmesani, A. (1993). A study of some psycho-social characteristics of blind and deaf male students in Abha City, Asir Region, Saudi. Public Health, Vol. 107 No. 4, pp. 261-269.

Barati, S. A., Barati, A. A., Gaeeni, S., Ghanbarzadeh, M. (2013). Comparing the effect of combination of mental and physical practices on balance capability of students with vision disorders. International Journal of Sport Studies, Vol. 31 No.1, pp. 80-85.

Bilge, B. C., Ummuhan, B. A., Sehmus, A., Elif, G. K. (2019). The effect of static and dynamic balance training 
on balance in children with congenital blindness. Journal of contemporary medicine, Vol. 9 No. 1, pp. 89-94. Çalık, B.B., Aslan, U.B., Aslan, S., Kabul, E.G. (2019). The effect of static and dynamic balance training on balance in children with congenital blindness. Journal of Contemporary Medicine, Vol. 9 No.1, pp. 89-94.

Çolak, T., Bamaç, B., Aydin, M., Meriç, B., Özbek, A. (2004). Physical fitness levels of blind and visually impaired goalball team players. Isokinetics and Exercise Science, Vol. 12 No. 4, pp. 247-255.

Haegele, J.A., Brian, A., Goodway, J. (2015). Fundamental motor skills and sSchool-aged individuals with visual impairments: a review. Review Journal of Autism and Developmental Disorders. Vol. 2 No.3, pp. 320-327.

Juodžbalienè, V., Muskus, K. (2006). The influence of the degree of visual impairment on psychomotor reaction and equilibrium maintenance of adolescents, Medicina (Kaunas), Vol. 42 No. 1, pp. 49-56.

King G., Law, M., King, S., Rosenbaum, P., Kertoy, M.K., Young, N.L. (2003). A conceptual model of the factors affecting the recreation and leisure participation of children with disabilities, Physical \& Occupational Therapy in Geriatrics, Vol. 23, No. 1, pp. 63-90.

Kozub, F., Oh, H. (2004). An exploratory study of physical activity levels in children and adolescents with visual impairments.Clinical Kinesiology, Vol. 58 No. 3, pp 1-7. Lieberman, L. J., Houston-Wilson, C., Kozub, F. M. (2002). Perceived barriers to including students with visual impairments in general physical education. Adapted Physical Activity Quarterly, Vol. 19 No. 3, pp. 364-377.

Longrnuir, P. E., Bar-Or, O. (2000). Factors influencing the physical activity levels of youths with physical and sensory disabilities. Adapted Physical Activity Quarterly, Vol. 17 No. 40, pp. 40-53.

O’sullivan, S.B., Portnry, L.G. (2014). Physical Rehabilitation: Sixth Edition, FA Davis, Philadelphia.

Perrin, P., Deviterne, D., Hugel, F., Perrot C. (2002).
Judo, beter than dance, develops sensorimotor adaptibilities involved in balance control. Gait and Posture, Vol. 15 No. 2, pp. 187-194.

Portfors-Yeomans, C. V., Riach, C. L. (1995). Frequency characteristics of postural control of children with and without visual impairment. Developmental Medicine and Child Neurology, Vol. 37 No. 5, pp. 456-463.

Rutkowska, I., Bednarczuk, G., Molik B., Morgulec-Adamowicz, N., Marszałek J, Kaźmierska-Kowalewska, K., Koc, K.. (2015), Balance functional assessment in people with visual impairment, Journal of Human Kinetics, Vol. 48 No. 1, pp. 99-109.

Rutkowska, I., Skowronski, W. (2007). A comparison of body balance of blind children aged 7-16 years in sex and age categories, Studies in Physical Culture and Tourism, Vol. 14, pp. 287-292.

Slanchev P. et al. (1992). Fizichesko razvitie, fizicheska deesposbnost i nervno-psihichna reaktivnost na naselenieto na Bulgaria. Sofia.

Sundberg, S. (1982). Maximal oxygen uptake in relation to age in blind and normal boys and girls. Acta Paediatrica, Vol. 71 No. 4, pp. 603-608.

Uzunović, S., Zdravković, G., Kostić, R., Pantelić, S., Milanović, Z., Jorgić, B., Aleksandrović, M. (2015). Comparison of the static balance of children with and without visual impairment, Research in Physical Education, Sport and Health, Vol. 4 No. 2, pp. 95-99.

WHO. ICD-10 Available at: http://apps.who.int/classifications/icd10/browse/2010/ en\#/H54

\section{Corresponding author: Irena Lyudmilova, Ph.D.} Assistant Professor National Sports Academy "Vassil Levski" Gurgulyat str. 1, Sofia,1000, Bulgaria E-mail: irenaludmilova@abv.bg 